\section{Kidney \\ Blood Pressure Research}

Kidney Blood Press Res 2015;40:111-120

DOI: $10.1159 / 000368487$

Published online: March 14, 2015

Accepted: February 03, 2015
(C) 2015 S. Karger AG, Basel www.karger.com/kbr

1423-0143/15/0402-0111\$39.50/0

\title{
hTERT, BICD1 and Chromosome 18 Polymorphisms Associated with Telomere Length Affect Kidney Allograft Function After Transplantation
}

\author{
Karolina Kłoda ${ }^{a} \quad$ Leszek Domanski ${ }^{a}$ \\ Krzysztof Safranow ${ }^{b} \quad$ Arleta Drozd ${ }^{c}$ \\ Agnieszka Maciejewska-Karłowska \\ Kazimierz Ciechanowski ${ }^{a}$
}

\author{
Ewa Kwiatkowska ${ }^{a}$ Ewa Borowieckaa, \\ Andrzej Ciechanowicz ${ }^{d}$ \\ Marek Sawczuk ${ }^{\mathrm{e}}$ Andrzej Pawlik
}

\begin{abstract}
${ }^{a}$ Clinical Department of Nephrology, Transplantology and Internal Medicine, Pomeranian Medical University; ${ }^{b}$ Department of Biochemistry and Medical Chemistry, Pomeranian Medical University; 'Department of Biochemistry and Human Nutrition, Pomeranian Medical University; ${ }^{\mathrm{d} D e p a r t m e n t}$ of Laboratory Diagnostics and Molecular Medicine, Pomeranian Medical University; ${ }^{\text {eFaculty of }}$ Physical Culture and Health Promotion, University of Szczecin; fDepartment of Pharmacokinetics and Therapeutic Drug Monitoring, Pomeranian Medical University in Szczecin, Szczecin, Poland
\end{abstract}

\section{Key Words}

Allograft • DGF • Gene • Polymorphism • Telomere length

\begin{abstract}
Background/Aims: It has been confirmed that telomere length (TL) correlates with chronological donor age and that telomere shortening is accelerated in allografts. The aim of this study was to analyse the associations between graft rs2735940 hTERT and rs2630578 BICD1 gene polymorphisms and rs7235755/rs2162440 chromosome 18 polymorphisms, relative TL and kidney function after transplantation. Methods: The study enrolled 119 Polish Caucasian kidney allograft recipients (64M/55F, mean age $47.3 \pm 14.0$ years). The relative $T L$ was assessed in biopsy specimens. To identify genotypes of the studied polymorphisms, real-time PCR was performed. Results: The graft rs2735940 hTERT gene polymorphism TT genotype was associated with a significantly lower risk of delayed graft function (DGF) (TT vs. TC+CC; $\mathrm{OR}=0, \mathrm{p}=0.009$ ) and significantly shorter TL in the ' 0 ' biopsy (TT vs. CC: $207 \pm 153$ vs. $400 \pm 161$, $\mathrm{p}=0.036)$. The graft rs 2630578 BICD1 gene polymorphism CC genotype was associated with lower creatinine concentrations in the first month (CC vs. GC: $1.11 \pm 0.06$ vs. $2.0 \pm 1.25 \mathrm{mg} / \mathrm{dL}$, $p=0.03$ ). The AA genotype of the graft rs 7235755 chromosome 18 polymorphism was associated with longer relative TL in specimens collected 12 to 60 months after transplantation (AA vs.
\end{abstract}

Karolina Kłoda and Leszek Domanski contributed equally to this work and thus share first authorship.

Andrzej Pawlik

KARGER 125
Department of Pharmacokinetics and Therapeutic Drug Monitoring, Pomeranian Medical University in Szczecin, Powstańców Wlkp. 72, 70-111 Szczecin (Poland)

E-Mail pawand@poczta.onet.pl 


\section{Kidney Blood Pressure Research}

Kidney Blood Press Res 2015;40:111-120

DOI: 10.1159/000368487

Published online: March 14, 2015

(c) 2015 S. Karger AG, Basel

www.karger.com/kbr

$G G+G A p=0.04$; $A A$ vs. $G G: 489 \pm 152$ vs. $246 \pm 145, p=0.035)$ and the presence of $A$ allele was associated with higher creatinine concentrations one month after transplantation (GA+AA vs. GG $p=0.026$; $G A$ vs. GG: $2.18 \pm 1.59$ vs. $1.76 \pm 0.88 \mathrm{mg} / \mathrm{dL}, \mathrm{p}=0.02$ ). It was found that shorter $\mathrm{TL}$ in the first six months was associated with higher creatinine concentrations 12 and 18 months after transplantation ( $R s=-0.32 ; p=0.07$ and $R s=-0.54 ; p=0.006$, respectively). Conclusions: Graft rs2735940 hTERT and rs2630578 BICD1 gene polymorphisms and rs7235755/rs2162440 chromosome 18 polymorphisms, apart from the association with TL, affect early kidney function after transplantation. Relative TL correlated negatively with creatinine concentrations, allowing the use of TL as a predictor of long-term kidney function.

Copyright $@ 2015$ S. Karger AG, Basel

\section{Introduction}

Telomere length (TL) has been analysed with regard to cell senescence and ageing of animals and humans, including age-related diseases [1-4]. There have been also attempts to link the accelerating transplanted organ ageing with TL and telomerase activity assessments $[5,6]$. The context of kidney transplantation outcome is currently of particular interest, because TL has turned out to be a determinant of post-transplant organ function [7]. The common organ shortage has resulted in expanding kidney donor criteria to over 60 years of age [8]. The effect of the biological organ age of the donated allograft is still unknown. It has been confirmed that TL correlates with chronological donor age and that telomere shortening is accelerated in allografts [5-7]. Reaching the limit of proliferative capacity may lead to organ failure and subsequent loss. The possibility of allograft vitality prediction would allow the stratification of donors and recipients in order to improve transplantation outcomes [6].

Telomerase, which is also called telomere terminal transferase, is an enzyme responsible for telomere elongation through adding DNA sequence repeats. Human telomerase consists of the catalytic subunits telomerase reverse transcriptase (TERT), telomerase RNA (TR or TERC), and dyskerin (DKC1). Therefore, there are several genes encoding telomerase subunits, including hTERT, TERC, DKC1 and TEP1 [9]. The hTERT gene is located on chromosome 5 and determines telomerase activity. There are over 200 hTERT gene polymorphisms influencing cell cycle and promoting cancer development [10]. Moreover, changes among the hTERT gene may be correlated not only with cell immortality, but also with telomere shortening. Among patients with peripheral arterial disease, the loss-of-function haplotype CC of the rs2735940 and rs2853669 hTERT gene polymorphisms has been associated with shorter TL [9]. The bicaudal D homolog 1 (BICD1) rs2630778 gene polymorphism has also been linked with telomere shortening [11]. However, the analysis of the rs2630578 BICD1 gene polymorphism in individuals with coronary heart disease and type 2 diabetes gave no significant results [12]. Other genetic loci (rs2162440 and rs7235755) found on chromosome 18 (18q12.2) in a two stage genome wide association (GWA) study on 2790 individuals from the UK were associated with shorter TL (C and G allele, respectively) [13]. All this evidence indicates that, apart from ageing, genetic factors significantly influence TL.

The aim of this study was to analyse the associations between graft rs2735940 hTERT and rs2630578 BICD1 gene polymorphisms and rs7235755/rs2162440 chromosome 18 polymorphisms, relative TL and kidney function after transplantation.

\section{Material and Methods}

Participants

The study enrolled 119 Polish Caucasian kidney allograft recipients (64M/55F, mean age 47.32 \pm 14.03 ; transplantation performed between 2001 and 2012). Organs were harvested from cadaveric donors 


\section{Kidney Blood Pressure Research}

(59.8\%M/40.2\%F, mean age $45.99 \pm 14.62$ years). The population of recipients was dived into subgroup A - up to 2 years after transplantation $(n=70)$ and subgroup B - more than 2 years after transplantation $(n=49)$. The division was necessary to set the inclusion criteria. Subgroup A included first renal allograft recipients recruited consecutively immediately after transplantation and after giving their consent to participate in the study, while subgroup B included the first renal allograft recipients with a functioning organ, recruited from the Transplant Outpatient Clinic that delivers ongoing care for kidney transplant recipients following discharge, after giving their consent to participate in the study. Exclusion criteria were: more than one renal transplantation, lack of consent, or organ loss/return to dialysis. Kidney allograft recipients' detailed characteristics are presented in Table 1. The main causes of impaired kidney function before transplantation were glomerulonephritis, type 1 and 2 diabetes (T1DM and T2DM), arterial hypertension and autosomal dominant polycystic kidney disease (ADPKD). Arterial hy-
Kidney Blood Press Res 2015;40:111-120

DOI: 10.1159/000368487

Published online: March 14, 2015

(C) 2015 S. Karger AG, Basel

www.karger.com/kbr

Kłoda/Domanski/Kwiatkowska et al.: Polymorphisms Associated with Telomere Length Affect Kidney Allograft Function

Table 1. Clinical characteristics of the studied group

\begin{tabular}{lcc}
\hline Recipients & (N or n/N) & Mean \pm SD or \% \\
\hline Mean age [years] & 119 & $47.32 \pm 14.03$ \\
Male Sex & $64 / 119$ & $53.8 \%$ \\
BMI [kg/m²] & 67 & $25.75 \pm 4.50$ \\
AH & $91 / 115$ & $79.1 \%$ \\
HD before Tx & $66 / 84$ & $78.6 \%$ \\
PD before Tx & $14 / 84$ & $16.64 \%$ \\
Preemptive Tx & $4 / 84$ & $4.76 \%$ \\
Mean time of D before Tx [months] & 80 & $28.02 \pm 19.65$ \\
Residual diuresis [mL/d] & 78 & $1201.9 \pm 1267.7$ \\
CIT [hours] & 93 & $17.7 \pm 6.65$ \\
PRA [\%] & 84 & $3.4 \pm 11.4$ \\
Diuresis 7th day after Tx [mL/d] & 43 & $3348.8 \pm 1646.1$ \\
Cr 7th day after Tx [mg/dL] & 98 & $3.35 \pm 2.62$ \\
Cr 1 month after Tx [mg/dL] & 100 & $1.88 \pm 1.45$ \\
Cr 6 months after Tx [mg/dL] & 72 & $1.50 \pm 0.52$ \\
Cr 12 months after Tx [mg/dL] & 74 & $1.50 \pm 0.59$ \\
Cr 24 months after Tx [mg/dL] & 56 & $1.62 \pm 1.11$ \\
DGF & $36 / 119$ & $30.25 \%$ \\
AR & $34 / 119$ & $28.57 \%$ \\
CAD & $17 / 119$ & $14.29 \%$ \\
Post Tx infection & $39 / 119$ & $32.8 \%$ \\
Post Tx UTI & $25 / 39$ & $64.1 \%$ \\
Post Tx CMV infection & $6 / 39$ & $15.38 \%$ \\
Post Tx BKV infection & $3 / 39$ & $7.69 \%$ \\
Post Tx TBC infection & $1 / 39$ & $2.56 \%$ \\
Post Tx Sepsis & $1 / 39$ & $2.56 \%$ \\
Mortality & $3 / 119$ & $2.52 \%$ \\
\hline n - numbr of recipients with & \\
\hline
\end{tabular}

$\mathrm{n}$ - number of recipients with indicated feature, $\mathrm{N}$ - number of all recipients with available data, SD - standard deviation, BMI - body mass index, AH - arterial hypertension, HD - hemodialysis, Tx transplantation, PD -peritoneal dialysis, D - dialysis, CIT - cold ischemia time, PRA - panel reactive antibody, $\mathrm{Cr}$ - creatinine, DGF delayed graft function, AR - acute rejection, CAD - chronic allograft dysfunction, UTI - urinary tract infection, CMV - cytomegalovirus, $\mathrm{BKV}$ - BK virus, TBC - tuberculosis

pertension, post-transplant diabetes (PTDM) and atherosclerosis were the main comorbid conditions.

The following parameters were recorded: the recipient and donor ages and gender, the recipient's body mass index (BMI), the type of dialysis treatment and its duration before transplantation, the cause of impaired kidney function, residual diuresis, panel reactive antibodies (PRA), cold ischaemia time (CIT), date of the transplantation, comorbid conditions, and the occurrence and type of infection after transplantation. The frequencies of delayed graft function (DGF), AR (acute rejection) and chronic allograft dysfunction (CAD) were observed. The diagnosis of DGF was determined as the need for dialysis during the first 7 days after transplantation. Identification of AR was confirmed clinically (pain and/or swelling of the kidney graft, body temperature $\geq 38^{\circ} \mathrm{C}$, elevated serum creatinine $\geq 25 \%$ in the absence of other pathology including infection, urinary tract obstruction, allograft artery stenosis, or cyclosporine and tacrolimus toxicity), and by biopsy review. The diagnosis of CAD was based on functional and morphological (biopsy confirmed) deterioration of a renal allograft at least 3-6 months after transplantation. Blood samples were collected for creatinine concentration evaluation during the first 7 days after transplantation, and 1, 3, 6, 12, 18, 24, 30, 36, 48 and 60 months after kidney transplantation. Creatinine concentration assessment was performed using a colorimetric method. Biopsy specimens were collected for analysis of the RTL and renal pathologist review (Banff working classification criteria were used) in the peri-transplant period (biopsy ' 0 ') , 3, 6, 12, 18, 24, 36, 48 and 60 months after transplantation and in the case of deteriorating renal transplant function. All patients received the standard 


\section{Kidney \\ Blood Pressure Research}

Kidney Blood Press Res 2015;40:111-120

\begin{tabular}{l|l}
\hline DOI: $10.1159 / 000368487$ & (C) 2015 S. Karger AG, Basel
\end{tabular}

Published online: March 14, 2015

www.karger.com/kbr

immunosuppressive protocol with triple drug therapy including a calcineurin inhibitor (tacrolimus), mycophenolate mofetil or mycophenolate sodium, and steroids. Some individuals in subgroup B received cyclosporine, azathioprine and steroids after transplantation, but were then converted to tacrolimus and mycophenolate mofetil at least 6 years prior to the study. If necessary, the immunosuppressive protocol was modified through everolimus or sirolimus initial administration/conversion. In some cases, induction immunosuppressive therapy was offered. Informed consent was obtained from all patients. The local ethics committee of the Pomeranian Medical University in Szczecin, Poland, approved protocol of the study.

\section{Relative TL analysis}

DNA was extracted using a mini column-based DNA isolation kit (A\&A Biotechnology, Gdynia, Poland) and stored at $-20^{\circ} \mathrm{C}$. A high concentration genomic DNA sample was prepared in decimal concentrations to cover all possible measurements. According to standard procedure, telomere length was assessed using two pairs of primers, i.e. telomere-specific and a single copy gene-specific (albumin). The design of primers specific to a difficult sequence of telomeres is challenging and there are already numerous protocols for this application $[14,15]$. We used the primers that had already been shown to work specifically [14], as we found them to be the most optimal of all of the primers tested in the context of specificity and to result in no primer-dimer or non-specific products.

The PCR conditions used to amplify the telomere fragment were as follows: initial denaturation and polymerase activation (hot start) was performed in $95^{\circ} \mathrm{C}$ for $10 \mathrm{~min}$ followed by two cycles of $94^{\circ} \mathrm{C} / 15 \mathrm{~s}$ and $49^{\circ} \mathrm{C} / 15 \mathrm{~s}$ without fluorescence acquisition. The signal was detected during another 40 cycles i.e. $94^{\circ} \mathrm{C} /$ $10 \mathrm{~s}, 66^{\circ} \mathrm{C} / 10 \mathrm{~s}$ and $72^{\circ} \mathrm{C} / 10 \mathrm{~s}$. Melting analysis $\left(65-95^{\circ} \mathrm{C}\right.$ range, $0.2^{\circ} \mathrm{C}$ resolution) at the end of the reaction was performed to verify the specificity of the product and indicated $\mathrm{Tm}=81.7$. The efficiency of the reaction was no lower than $97.8 \%$. Importantly, this result was repeatable for all of the samples that were analysed (in serial dilutions). After the optimisation of the primer concentration, which was estimated to be $0.5 \mu \mathrm{M}$, we selected the optimal magnesium chloride concentration of $2.5 \mathrm{mM}$. Similarly, reaction conditions used to identify the optimal annealing temperature, magnesium chloride and primer concentrations for albumin were as follows: denaturation $95^{\circ} \mathrm{C} / 10 \mathrm{~min}$ - hot start; followed by 45 cycles $94^{\circ} \mathrm{C} / 10 \mathrm{~s}, 61^{\circ} \mathrm{C} / 10 \mathrm{~s}$ and $72 / 10 \mathrm{~s}$. The Tm of the product (analysis performed as above) was $80.7^{\circ} \mathrm{C}$ and the efficiency was $99.6 \%$. The concentration of primers was $0.5 \mu \mathrm{M}$ and magnesium chloride $2.5 \mathrm{mM}$. The telomere length was assessed using a qPCR system (Roche, LC 2.0) and SybrGreen kit (Roche, Manheim, Germany).

hTERT, BICD1 and chromosome 18 polymorphisms analysis

All samples were genotyped in duplicate using allelic discrimination assays with Taqman ${ }^{\circledR}$ probes (Applied Biosystems, Carlsbad, California, USA) on a CFX96 Touch $^{\mathrm{TM}}$ Real-Time PCR Detection System (BioRad, Hercules, California, USA). To discriminate $h T E R T$ rs2735940, BICD1 rs2630578 as well as chromosome 18 rs7235755 and rs2162440 alleles, TaqMan® Pre-Designed SNP Genotyping Assays were used (assay IDs: C__2412786_10, C__7497299_10 and C_15966471_20, respectively), including appropriate primers and fluorescently labelled (FAM and VIC) MGB ${ }^{\text {TM }}$ probes to detect the alleles. Genotypes were assigned using all of the data from the study simultaneously.

\section{Statistical analysis}

The distribution of the genotypes and alleles was evaluated with use of the chi-square test or Fisher's exact test. Since distributions of most quantitative variables were significantly different from a normal distribution $(\mathrm{p}<0.05$, Shapiro-Wilk test), we used non-parametric tests. Spearman's rank correlation coefficient was used to analyse correlations between variables and the Kruskal-Wallis test followed by Mann-Whitney $\mathrm{U}$ test were used to compare values between groups. Associations with a p-value $<0.05$ were considered statistically significant. Calculations were performed with Statistica 10 software.

\section{Results}

The frequency distribution of the rs2735940 hTERT gene, rs2630578 BICD1 gene, as well as rs7235755 and rs2162440 within chromosome 18 polymorphisms genotypes among grafts are presented in Table 2 . Because of full linkage disequilibrium between the 


\section{Kidney \\ Blood Pressure Research}

Table 2. The frequency distribution of studied polymorphisms genotypes among grafts

Table 3. The distributions of the grafts' genotypes and alleles of the rs2735940 hTERT gene polymorphism in recipients with and without DGF

\begin{tabular}{|c|c|c|c|c|c|c|c|c|}
\hline \multirow[b]{2}{*}{$\begin{array}{l}\text { Genotypes and } \\
\text { alleles; rs2735940 }\end{array}$} & \multicolumn{2}{|c|}{ DGF $(n=27)$} & \multicolumn{3}{|c|}{$\begin{array}{l}\text { Without DGF } \\
(n=60)\end{array}$} & \multirow[b]{2}{*}{ Comparison } & \multirow[b]{2}{*}{$\begin{array}{l}\text { OR }(95 \% \mathrm{CI}) \\
\text { for DGF }\end{array}$} & \multirow[b]{2}{*}{$\mathrm{p}^{*}$} \\
\hline & $\mathrm{n}$ & $\%$ & $\mathrm{n}$ & $\%$ & $\mathrm{p}^{\wedge}$ & & & \\
\hline $\mathrm{CC}$ & 7 & 27.0 & 19 & 73.0 & & TT vs TC+CC & $0.00(-)$ & 0.009 \\
\hline TC & 20 & 41.7 & 28 & 58.3 & 0.01 & TT vs TC & $0.00(-)$ & 0.005 \\
\hline TT & 0 & 0.0 & 13 & 100.0 & & TT vs CC & $0.00(-)$ & 0.04 \\
\hline $\mathrm{C}$ & 34 & 34.0 & 66 & 66.0 & & T vs C & $0.72(0.37-1.39)$ & 0.326 \\
\hline $\mathrm{T}$ & 20 & 27.0 & 54 & 73.0 & & & & \\
\hline
\end{tabular}

\section{Kidney Blood Press Res 2015;40:111-120}

DOI: 10.1159/000368487

Published online: March 14, 2015

C 2015 S. Karger AG, Basel

www.karger.com/kbr
Kłoda/Domanski/Kwiatkowska et al.: Polymorphisms Associated with Telomere Length Affect Kidney Allograft Function

\begin{tabular}{lccc}
\hline & \multicolumn{3}{c}{ Genotypes frequency (\%) } \\
\hline Polymorphism & CC n (\%) & CT n (\%) & TT n (\%) \\
hTERT rs2735940 & 26 (30\%) & 48 (55\%) & $13(15 \%)$ \\
Polymorphism & GG n (\%) & GC n (\%) & CC n (\%) \\
BICD1 rs2630578 & $61(70 \%)$ & $23(26.5 \%)$ & $3(3.5 \%)$ \\
Polymorphism & GG n (\%) & GA n (\%) & AA n (\%) \\
C18 rs7235755* & $51(58.5 \%)$ & $31(35.5 \%)$ & $5(6 \%)$ \\
\hline * rs7235755 G and A alleles are equivalent to rs2162440 C and T \\
alleles, respectively
\end{tabular}

chromosome 18 polymorphisms (rs7235755 G and A alleles are equivalent to rs2162440 $\mathrm{C}$ and $\mathrm{T}$ alleles, respectively), we present only rs7235755 genotypes. The distribution of all studied polymorphisms was consistent with Hardy-Weinberg equilibrium $(p=0.28 ; p=0.7$ and $\mathrm{p}=1.0$ respectively).

Association between studied polymorphisms and DGF

Delayed graft function was diagnosed in $27.0 \%$ of recipients with the graft rs 2735940 hTERT gene polymorphism CC genotype, in $41.7 \%$ of those with the TC graft genotype, and in $0.0 \%$ of those with TT. There were no TT graft genotype carriers with a diagnosis of DGF; therefore, it was impossible to assess the confidence intervals (TT vs TC+CC $p=0.009$ ) (Table 3). There were no statistically significant differences between recipients with DGF and without DGF in regard to the rs2630578 BICD1 gene polymorphism, or rs7235755/ rs2162440 within the graft chromosome 18 genotypes.

Association between studied polymorphisms and biopsy specimens relative TL

Table 4 presents the relative graft TL in kidney biopsy specimens stratified according to the rs2735940 hTERT gene, rs2630578 BICD1 gene and rs7235755/rs2162440 chromosome 18 polymorphisms. The differences between relative TL in kidney biopsy specimens collected at month '0' with regard to all rs2735940 hTERT gene polymorphism genotypes were on the border of statistical significance $(\mathrm{p}=0.09)$. However, the comparison between two genotypes showed that relative TL was significantly shorter in the TT allograft specimens vs. CC genotype carriers $(\mathrm{p}=0.036)$. Similarly, allograft specimens with a T allele of the rs 2735940 $h T E R T$ gene polymorphism collected from month ' 0 ' to the sixth month after transplantation were characterized with a shorter relative TL in comparison to CC homozygotes $(p=0.047)$. Relative TL in biopsy specimens collected 12 to 60 months after transplantation was shorter in $\mathrm{T}$ allele carriers in comparison to CC homozygotes; however these differences were on the border of statistical significance $(\mathrm{p}=0.089)$. A comparison of all $\mathrm{rs} 2630578$ BICD1 gene polymorphism genotypes with regard to relative TL in biopsy specimens collected at different time points revealed no statistically significant differences. The AA homozygotes of the graft rs7235755 chromosome 18 polymorphism in biopsy specimens collected from month ' 0 ' to the sixth month after transplantation were characterized with significantly shorter TL $(\mathrm{GG}+\mathrm{GA}$ vs. $\mathrm{AA} \mathrm{p}=0.027$ and $\mathrm{GG}$ vs $\mathrm{AA} \mathrm{p}=0.05)$. However, the comparison between genotypes 


\section{Kidney \\ Blood Pressure Research}

Kidney Blood Press Res 2015;40:111-120

DOI: $10.1159 / 000368487$

Published online: March 14, 2015

(C) 2015 S. Karger AG, Basel

www.karger.com/kbr

Table 4. Grafts' relative telomere length in kidney biopsies specimens stratified according to rs2735940 hTERT gene, rs2630578 BICD1 gene and rs7235755/rs2162440 chromosome 18 polymorphisms genotypes

\begin{tabular}{|c|c|c|c|c|c|c|}
\hline GRTL & Mean \pm SD & Mean \pm SD & Mean \pm SD & $\mathrm{p}^{\wedge}$ & $\mathrm{p}^{*}$ & p* \\
\hline \multicolumn{7}{|c|}{ rs2735940 hTERT } \\
\hline & CC & $\mathrm{TC}$ & $\mathrm{TT}$ & & CC vs CT & TT vs CC \\
\hline Biopsy $0 \mathrm{~m}$ & $400 \pm 161$ & $293 \pm 153$ & $207 \pm 153$ & 0.09 & 0.14 & 0.036 \\
\hline Biopsy 0-6 m & $330 \pm 117$ & $263 \pm 136$ & $267 \pm 195$ & 0.13 & 0.047 & 0.24 \\
\hline Biopsy $12-60 \mathrm{~m}$ & $343 \pm 133$ & $241 \pm 182$ & $278 \pm 236$ & 0.23 & 0.089 & 0.66 \\
\hline \multicolumn{7}{|c|}{ rs2630578 BICD1 } \\
\hline & GG & GC & $\mathrm{CC}$ & & GG vs GC & GG vs CC \\
\hline Biopsy $0 \mathrm{~m}$ & $325 \pm 180$ & $305 \pm 126$ & $215 \pm 106$ & 0.61 & 0.44 & 0.39 \\
\hline Biopsy 0-6 m & $290 \pm 147$ & $285 \pm 135$ & $202 \pm 79$ & 0.49 & 0.26 & 0.95 \\
\hline Biopsy $12-60 \mathrm{~m}$ & $270 \pm 166$ & $308 \pm 187$ & -\# & - & 0.59 & - \\
\hline \multicolumn{7}{|c|}{ rs7235755 chromosome 18} \\
\hline & GG & GA & $\mathrm{AA}$ & & $\mathrm{GG}+\mathrm{GA}$ vs $\mathrm{AA}$ & GG vs AA \\
\hline Biopsy 0 m & $300 \pm 178$ & $338 \pm 139$ & $-\#$ & - & - & - \\
\hline Biopsy 0-6 m & $285 \pm 151$ & $304 \pm 118$ & $90 \pm 26$ & 0.09 & 0.027 & 0.05 \\
\hline Biopsy 12-60 m & $246 \pm 145$ & $286 \pm 193$ & $489 \pm 152$ & 0.11 & 0.04 & 0.035 \\
\hline
\end{tabular}

${ }^{\wedge}$ Kruskal-Wallis (K-W) test for differences between 3 genotypes, *Mann-Whitney test, " no biopsies with indicated graft genotype were available, SD - standard deviation, GRTL - grafts' relative telomere length, $\mathrm{m}$ - month

in specimens collected 12 to 60 months transplantation showed significantly longer TL among AA homozygotes (GG+GA vs. AA p=0.04 and GG vs AA p=0.035).

Association between studied polymorphisms and creatinine concentrations

Table 5 presents the creatinine serum concentrations of recipients stratified according to the graft rs2735940 hTERT gene, rs2630578 BICD1 gene and rs7235755/rs2162440 chromosome 18 polymorphisms. A comparison of creatinine concentrations assessed at different time points $(1,6,12$ and 24 months after transplantation) with regard to the graft rs2735940 hTERT gene polymorphism showed no statistically significant differences. Creatinine concentrations 1 and 6 months after transplantation differed among the graft rs2630578 BICD1 gene polymorphism genotypes ( $\mathrm{p}=0.067$ and 0.049 , respectively) and were lower among the CC homozygotes (GC vs. CC p=0.03 and GC vs. CC $p=0.067$, respectively). Differences in creatinine concentrations 12 and 24 months after transplantation with regard to rs2630578 BICD1 gene polymorphism genotypes were not statistically significant. Creatinine concentrations one month after transplantation differed among the graft rs7235755 chromosome 18 polymorphism genotypes $(\mathrm{p}=0.08)$ and were higher among the A allele carriers ( $G A+A A$ vs. $G G p=0.026$ and $G G$ vs $G A p=0.02$ ). A comparison of creatinine concentrations assessed 6,12 and 24 months after transplantation with regard to graft rs7235755 chromosome 18 polymorphism genotypes showed no statistically significant differences.

Correlations between creatinine serum concentrations and biopsy specimen relative TL

The analysis of relative TL in kidney allograft biopsy specimens collected at different time points and creatinine concentrations revealed negative correlations (presented in detail in Table 6). The higher the concentration of creatinine assessed in the first week after transplantation (third and seventh day), the shorter the TL in biopsies performed between 12 and 24 months after transplantation (borderline statistical significance, $\mathrm{p}<0.1$ ). Moreover, the shorter TL in the early period after transplantation (0-6 months), the higher the creatinine concentrations 12 and 18 months after transplantation $(\mathrm{p}=0.07$ and $\mathrm{p}=0.006$ respectively). The correlation between TL at 0-6 months and creatinine concentration at 24 months after transplantation was not statistically significant. 


\section{Kidney \\ Blood Pressure Research}

Kidney Blood Press Res 2015;40:111-120

DOI: $10.1159 / 000368487$

Published online: March 14, 2015

(C) 2015 S. Karger AG, Basel

www.karger.com/kbr

Table 5. Recipients' creatinine serum concentrations stratified according to grafts' rs2735940 hTERT gene, rs2630578 BICD1 gene and rs7235755/ rs2162440 chromosome 18 polymorphisms genotypes

\begin{tabular}{|c|c|c|c|c|c|c|c|}
\hline $\mathrm{Cr}[\mathrm{mg} / \mathrm{dl}]$ & Mean \pm SD & Mean \pm SD & Mean \pm SD & $\mathrm{p}^{\wedge}$ & \multicolumn{2}{|c|}{$\mathrm{p}^{*}$} & $\mathrm{p}^{*}$ \\
\hline \multicolumn{8}{|c|}{ rs2735940 hTERT } \\
\hline & $\mathrm{CC}$ & $\mathrm{CT}$ & $\mathrm{TT}$ & & \multicolumn{2}{|c|}{ CC vs CT } & CC vs TT \\
\hline Creatinine $1 \mathrm{~m}$ & $1.60 \pm 0.57$ & $2.04 \pm 1.76$ & $1.43 \pm 0.44$ & 0.71 & \multicolumn{2}{|c|}{0.88} & 0.43 \\
\hline Creatinine $6 \mathrm{~m}$ & $1.31 \pm 0.32$ & $1.46 \pm 0.51$ & $1.55 \pm 0.44$ & 0.49 & \multicolumn{2}{|c|}{0.41} & 0.27 \\
\hline Creatinine $12 \mathrm{~m}$ & $1.38 \pm 0.63$ & $1.48 \pm 0.57$ & $1.44 \pm 0.45$ & 0.62 & \multicolumn{2}{|c|}{0.42} & 0.41 \\
\hline Creatinine $24 \mathrm{~m}$ & $1.34 \pm 0.40$ & $1.80 \pm 1.59$ & $1.42 \pm 0.46$ & 0.62 & \multicolumn{2}{|c|}{0.38} & 0.59 \\
\hline \multicolumn{8}{|c|}{ rs2630578 BICD1 } \\
\hline & GG & GC & $\mathrm{CC}$ & & \multicolumn{2}{|c|}{ CC vs GC } & CC vs GG \\
\hline Creatinine $1 \mathrm{~m}$ & $1.81 \pm 1.44$ & $2.0 \pm 1.25$ & $1.11 \pm 0.06$ & 0.067 & \multicolumn{2}{|c|}{0.03} & 0.089 \\
\hline Creatinine $6 \mathrm{~m}$ & $1.40 \pm 0.46$ & $1.59 \pm 0.41$ & $1.02 \pm 0.04$ & 0.049 & \multicolumn{2}{|c|}{0.067} & 0.16 \\
\hline Creatinine $12 \mathrm{~m}$ & $1.37 \pm 0.56$ & $1.60 \pm 0.59$ & $1.54(-)$ & 0.20 & \multicolumn{2}{|c|}{0.10} & 0.10 \\
\hline Creatinine $24 \mathrm{~m}$ & $1.61 \pm 1.43$ & $1.58 \pm 0.60$ & $1.46(-)$ & 0.35 & \multicolumn{2}{|c|}{0.35} & 0.35 \\
\hline \multicolumn{8}{|c|}{ rs7235755 chromosome 18} \\
\hline & GG & $\mathrm{GA}$ & AA & & \multicolumn{2}{|c|}{$\mathrm{GA}+\mathrm{AA}$ vs $\mathrm{GG}$} & GG vs GA \\
\hline Creatinine $1 \mathrm{~m}$ & $1.61 \pm 1.23$ & $2.18 \pm 1.59$ & $1.76 \pm 0.88$ & 0.08 & \multicolumn{2}{|c|}{0.026} & 0.02 \\
\hline Creatinine $6 \mathrm{~m}$ & $1.46 \pm 0.47$ & $1.40 \pm 0.47$ & $1.33 \pm 0.24$ & 0.94 & \multicolumn{2}{|c|}{0.84} & 0.92 \\
\hline Creatinine $12 \mathrm{~m}$ & $1.48 \pm 0.60$ & $1.34 \pm 0.56$ & $1.48 \pm 0.42$ & 0.51 & \multicolumn{2}{|c|}{0.49} & 0.31 \\
\hline Creatinine $24 \mathrm{~m}$ & $1.76 \pm 1.46$ & $1.24 \pm 0.36$ & $1.59 \pm 0.46$ & 0.15 & \multicolumn{2}{|c|}{0.71} & 0.29 \\
\hline \multicolumn{8}{|c|}{$\begin{array}{l}\text { ^Kruskal-Wallis (K-W) test for differences between } 3 \text { genotypes, *Mann-Whitney test, SD - } \\
\text { standard deviation, } \mathrm{Cr} \text { - creatinine, } \mathrm{m} \text { - month }\end{array}$} \\
\hline \multirow{9}{*}{$\begin{array}{l}\text { Table 6. Correla- } \\
\text { tions between } \\
\text { creatinine serum } \\
\text { concentrations as- } \\
\text { sessed at different } \\
\text { time points and } \\
\text { relative telomere } \\
\text { biopsy specimens } \\
\text { length }\end{array}$} & \multicolumn{4}{|c|}{ Correlated parameters } & $\mathrm{N}$ & Rs & $\mathrm{p}$ value \\
\hline & \multicolumn{4}{|c|}{$3^{\text {rd }}$ day creatinine $\& 12$ months biopsy } & 19 & -0.41 & 0.08 \\
\hline & \multicolumn{4}{|c|}{$3^{\text {rd }}$ day creatinine $\& 12-24$ months biopsy } & 29 & -0.36 & 0.06 \\
\hline & \multicolumn{4}{|c|}{$7^{\text {th }}$ day creatinine $\& 12$ months biopsy } & 23 & -0.37 & 0.08 \\
\hline & \multicolumn{4}{|c|}{$7^{\text {th }}$ day creatinine \& $12-24$ months biopsy } & 36 & -0.29 & 0.08 \\
\hline & \multirow{2}{*}{\multicolumn{4}{|c|}{$12^{\text {th }}$ month creatinine \& 0-6 months biopsy }} & 33 & -0.32 & 0.07 \\
\hline & $18^{\text {th }}$ month creatinine $\&$ 0-6 months biopsy & & & & 24 & -0.54 & 0.006 \\
\hline & \multicolumn{4}{|c|}{ 24th month creatinine \& 0-6 months biopsy } & 25 & -0.15 & 0.48 \\
\hline & \multicolumn{7}{|c|}{ p value calculated for Spearman's rank correlation coefficient (Rs) } \\
\hline
\end{tabular}

\section{Discussion}

Our main findings suggest that the TT genotype in the graft rs2735940 hTERT gene polymorphism is associated with a lower risk of DGF and the T allele is associated with shorter relative TL in the early period after transplantation. The G allele of the graft rs2630578 BICD1 gene polymorphism is associated with higher creatinine concentrations in the early period after transplantation. The A allele in the graft rs 7235755 chromosome 18 polymorphism is associated with longer relative TL in biopsy specimens collected 12 to 60 months after transplantation and higher creatinine concentrations in the early period after transplantation. Moreover, with a shorter TL in the early period after transplantation, higher creatinine concentrations were observed 12 and 18 months after transplantation. Moreover, a higher concentration of creatinine assessed in the first week after transplantation was associated with shorter TL in biopsies performed between 12 and 24 months after transplantation.

We observed associations between polymorphisms in genes implicated in the immune response and renal allograft function in our earlier studies [16-18]. The current study assessed the linkage between inflammation and accelerated ageing of the transplanted kidney. Results described elsewhere indicate that the age of the donor, the duration of 


\section{Kidney Blood Pressure Research}

Kidney Blood Press Res 2015;40:111-120

\begin{tabular}{l|l}
\hline DOI: $10.1159 / 000368487$ & (C) 2015 S. Karger AG, Basel
\end{tabular}

Published online: March 14, 2015

www.karger.com/kbr

dialysis before transplantation and PRA are negatively significantly correlated with relative TL. Moreover, we observed significant shortening of the TL in patients with DGF, AR and CAD. The strong association between the age of the donor and TL have been reported by other authors. Oetting et al. confirmed that ageing as a controlled biological process affects the transplanted kidney, leading to shortening of the TL [6]. In a study by Melk et al., somatic cell senescence mechanisms were found to influence kidney transplant outcomes through not only the age of the donor, but also through transplantation complications resulting in accelerated kidney allograft ageing [19]. Analysis of the polymorphisms associated with TL gives additional information on the predicted transplanted organ function. A significant decrease in TL and accelerated tissue senescence in primate kidneys exposed to the ischemiareperfusion injury has been reported [20]. Independently of ischemia-reperfusion damage leading to telomere shortening, we observed that the TT genotype of the graft rs 2735940 hTERT gene polymorphism is associated with a lower risk of DGF. The possible mechanism underlying this finding is not clear. We assume that the TT genotype of the rs 2735940 polymorphism may play a protective role in the pathogenesis of DGF by altering telomerase transcription activity. Iizuka et al. found that the TT genotype of the rs2735940 hTERT gene polymorphism is associated with a significantly lower risk of epithelial malignancy [21]. Unfortunately, the authors made no attempt to explain this observation. Since neoplasm promotion results from uncontrolled cell division, the TT genotype may be implicated in telomerase activity control and thereby affect the cell cycle. Such an assumption is in agreement with a study by Zhang et al., where the TT genotype was associated with longer TL in comparison with the CC genotype, which had $43 \%$ lower transcription activity of the hTERT promoter [9]. Contrary to this evidence, in our study, the T allele of the rs2735940 hTERT gene polymorphism was associated with shorter relative TL in the biopsy specimens collected between 0 and 6 months after transplantation. However, this could be explained by the frequency of DGF occurrence. There were no grafts with the TT genotype among patients with DGF and therefore no specimens were collected in the first 7 days after transplantation. Obviously, TT genotype graft biopsies performed in month ' 0 ' were mostly from the preimplantation period (during cold ischemia time). It is possible that the ischemic state affects rs2735940 hTERT gene polymorphism expression resulting in alterations in TL.

The rs2630578 BICD1 gene polymorphism $C$ allele has been linked to shorter TL and 44\% lower BICD1 mRNA levels in comparison to the G allele [11]. Analysis of this polymorphism among individuals with psychiatric disorders gave no significant results [22]. However, a study on patients with hypertension and cardiac organ damage revealed that the rs2630578 BICD1 gene polymorphism is associated with impaired function of heart muscle and lower ejection fraction. The $\mathrm{G}$ allele of this polymorphism showed a stronger association than the $C$ allele [23]. In our study, higher creatinine concentrations in the early period after transplantation were observed among grafts with the G allele of the rs2630578 BICD1 gene polymorphism. These results cannot be compared because of a lack of similar studies.

Studies concerning markers of cellular senescence, including TL as a predictor of kidney function, have focused mainly on the first year after transplantation. The authors of these reports claim that the cell cycle inhibitor CDKN2A rather than TL is the best single allograft outcome prognostic factor $[24,25]$. There have also been attempts to link long-term kidney function with TL. It has been shown that shorter TL is associated with impaired kidney function five years, but this observation could be explained by older age. Moreover, this study regarded individuals with stable coronary heart disease and not transplanted kidneys [26]. We found that the A allele of the graft rs7235755 chromosome 18 polymorphisms was associated with longer relative TL in biopsy specimens collected 12 to 60 months after transplantation. Despite the fact that there are no studies on kidney allografts to compare with our results, Mangino et al. confirmed that the G allele of the rs7235755 polymorphism is correlated with shorter TL [13]. Surprisingly, biopsy specimens with the A allele collected 0-6 months after transplantation had shorter telomeres. However, this sample was very small and therefore not representative. The A allele of the rs7235755 polymorphisms was associated with higher creatinine concentrations in the early period after transplantation in 


\section{Kidney \\ Blood Pressure Research}

\section{Kidney Blood Press Res 2015;40:111-120}

\begin{tabular}{l|l}
\hline DOI: $10.1159 / 000368487$ & (C) 2015 S. Karger AG, Basel
\end{tabular}

Published online: March 14, 2015

www.karger.com/kbr

our study. We cannot explain the possible underlying mechanism of this observation. It may be due to the influence of ischemia-reperfusion damage and DGF occurrence. Maubaret et al. found no association between the rs 2162440 chromosome 18 polymorphism and mean leukocyte TL and the risk of coronary artery disease [12]. It is possible that the impact of rs7235755/rs2162440 on the relative TL and kidney allografts is small and a much larger sample is needed to obtain reliable results.

The main limitation of our study is the small sample size. We observed many results on the border of statistical significance. Increasing the power of the study would allow us to obtain more reliable results. Unfortunately, the unavailability of funding made it impossible to recruit other transplantation centres. However, our findings give new insight into the association between TL-affecting polymorphisms and kidney allograft function.

\section{Conclusions}

Graft rs2735940 hTERT and rs2630578 BICD1 gene polymorphisms and rs7235755/ rs2162440 chromosome 18 polymorphisms, apart from an association with TL, affect early kidney function after transplantation. The results of the assessment of relative TL correlate negatively with creatinine concentrations, allowing us to use TL as a predictor of long-term kidney function.

\section{Disclosure Statement}

The authors of this manuscript state that they do not have any conflict of interests and nothing to disclose.

\section{Acknowledgements}

The research leading to these results has received funding from budgetary resources devoted to science in years 2013-2015 as a research project no NN 402487739.

\section{References}

1 Needham BL, Diez Roux AV, Bird CE, Bradley R, Fitzpatrick AL, Jacobs DR, Ouyang P, Seeman TE, Thurston RC, Vaidya D, Wang S: A test of biological and behavioral explanations for gender differences in telomere length: the multi-ethnic study of atherosclerosis. Biodemography Soc Biol 2014;60:156-173.

2 Baragetti A, Palmen J, Garlaschelli K, Grigore L, Pellegatta F, Tragni E, Catapano AL, Humphries SE, Norata GD, Talmud PJ: Telomere shortening over 6 years is associated with increased subclinical carotid vascular damage and worse cardiovascular prognosis in the general population. J Intern Med 2014, DOI 10.1111/ joim.12282.

3 Cai Z, Yan LJ, Ratka A: Telomere shortening and Alzheimer's disease. Neuromolecular Med 2013;15:25-48.

4 Syed FA, Ng AC: The pathophysiology of the aging skeleton. Curr Osteoporos Rep 2010;8:235-240.

5 Aini W, Miyagawa-Hayashino A, Ozeki M, Adeeb S, Hirata M, Tamaki K, Uemoto S, Haga H: Accelerated telomere reduction and hepatocyte senescence in tolerated human liver allografts. Transpl Immunol 2014;31:55-59.

6 Oetting WS, Guan W, Schladt DP, Wildebush WA, Becker J, Thyagarajan B, Jacobson PA, Matas AJ, Israni AK: Telomere length of recipients and living kidney donors and chronic graft dysfunction in kidney transplants. Transplantation 2014;97:325-329.

7 Gingell-Littlejohn M, McGuinness D, McGlynn LM, Kingsmore D, Stevenson KS, Koppelstaetter C, Clancy MJ, Shiels PG: Pre-transplant CDKN2A expression in kidney biopsies predicts renal function and is a future component of donor scoring criteria. PLoS One 2013;8:e68133. 


\section{Kidney \\ Blood Pressure Research}

Kidney Blood Press Res 2015;40:111-120

\begin{tabular}{l|l}
\hline DOI: $10.1159 / 000368487$ & C 2015 S. Karger AG, Basel \\
\hline
\end{tabular}

Published online: March 14, 2015

www.karger.com/kbr

8 Iordanous Y, Seymour N, Young A, Johnson J, Iansavichus AV, Cuerden MS, Gill JS, Poggio E, Garg AX; Donor Nephrectomy Outcomes Research (DONOR) Network: Recipient outcomes for expanded criteria living kidney donors: the disconnect between current evidence and practice. Am J Transplant 2009;9:1558-1573.

9 Zhang W, Chen Y, Yang X, Fan J, Mi X, Wang J, Zhang C, Hu FB, Hui R: Functional haplotypes of the hTERT gene, leukocyte telomere length shortening, and the risk of peripheral arterial disease. PLoS One 2012;7:e47029.

10 Mocellin S, Verdi D, Pooley KA, Landi MT, Egan KM, Baird DM, Prescott J, De Vivo I, Nitti D: Telomerase reverse transcriptase locus polymorphisms and cancer risk: a field synopsis and meta-analysis. J Natl Cancer Inst 2012;104:840-854.

11 Mangino M, Brouilette S, Braund P, Tirmizi N, Vasa-Nicotera M, Thompson JR, Samani NJ: A regulatory SNP of the BICD1 gene contributes to telomere length variation in humans. Hum Mol Genet 2008;17:25182523.

12 Maubaret CG, Salpea KD, Romanoski CE, Folkersen L, Cooper JA, Stephanou C, Li KW, Palmen J, Hamsten A, Neil A, Stephens JW, Lusis AJ, Eriksson P, Talmud PJ, Humphries SE; Simon Broome Research Group; EARSII consortium: Association of TERC and OBFC1 haplotypes with mean leukocyte telomere length and risk for coronary heart disease. PLoS One 2013;8:e83122.

13 Mangino M, Richards JB, Soranzo N, Zhai G, Aviv A, Valdes AM, Samani NJ, Deloukas P, Spector TD: A genome-wide association study identifies a novel locus on chromosome 18q12.2 influencing white cell telomere length. J Med Genet 2009;46:451-454.

14 Cawthon RM: Telomere length measurement by a novel mono-chrome multiplex quantitative PCR method. Nucleic Acids Res 2009;37:e21.

15 O'Callaghan NJ, Fenech M: A quantitative PCR method for measuring absolute telomere length. Biol Proced Online 2011;13:3.

16 Kłoda K, Domański L, Pawlik A, Safranow K, Ciechanowski K: The impact of ICAM1 and VCAM1 gene polymorphisms on long-term renal transplant function and recipient outcomes. Ann Transplant 2013;18:231-237.

17 Kłoda K, Domanski L, Bobrek-Lesiakowska K, Pawlik A, Safranow K, Kwiatkowska E, Wiśniewska M, Romanowski M, Ciechanowski K: The impact of CTLA4 and PTPN22 genes polymorphisms on long-term renal allograft function and transplant outcomes. Ren Fail 2013;35:1223-1227.

18 Kwiatkowska E, Domanski L, Kłoda K, Pawlik A, Safranow K, Ciechanowski K: IL2-IL21 gene cluster polymorphism is not associated with allograft function after kidney transplantation. Int Urol Nephrol 2014;46:2415-2420.

19 Melk A, Schmidt BM, Braun H, Vongwiwatana A, Urmson J, Zhu LF, Rayner D, Halloran PF: Effects of donor age and cell senescence on kidney allograft survival. Am J Transplant 2009;9:114-123.

20 Chkhotua AB, Schelzig H, Wiegand P, Grosse S, Reis S, Art M, Abendroth D: Influence of ischaemia/ reperfusion and LFA-1 inhibition on telomere lengths and CDKI genes in ex vivo haemoperfusion of primate kidneys. Transpl Int 2005;17:692-698.

21 Iizuka T, Sawabe M, Takubo K, Liu M, Homma Y, Suzuki M, Arai T: hTERT promoter polymorphism, $-1327 \mathrm{C}>\mathrm{T}$, is associated with the risk of epithelial cancer. Springerplus 2013;2:249.

22 Zhang D, Cheng L, Craig DW, Redman M, Liu C: Cerebellar telomere length and psychiatric disorders. Behav Genet 2010;40:250-254.

23 Huber M, Treszl A, Wehland M, Winther I, Zergibel I, Reibis R, Bolbrinker J, Stoll M, Schönfelder G, Wegscheider K, Völler H, Kreutz R: Genetic variants implicated in telomere length associated with left ventricular function in patients with hypertension and cardiac organ damage. J Mol Med (Berl) 2012;90:1059-1067.

24 Gingell-Littlejohn M, McGuinness D, McGlynn LM, Kingsmore D, Stevenson KS, Koppelstaetter C, Clancy MJ, Shiels PG: Pre-transplant CDKN2A expression in kidney biopsies predicts renal function and is a future component of donor scoring criteria. PLoS One 2013;8:e68133.

25 Koppelstaetter C, Schratzberger G, Perco P, Hofer J, Mark W, Ollinger R, Oberbauer R, Schwarz C, Mitterbauer C, Kainz A, Karkoszka H, Wiecek A, Mayer B, Mayer G: Markers of cellular senescence in zero hour biopsies predict outcome in renal transplantation. Aging Cell 2008;7:491-497.

26 Bansal N, Whooley MA, Regan M, McCulloch CE, Ix JH, Epel E, Blackburn E, Lin J, Hsu CY: Association between kidney function and telomere length: the heart and soul study. Am J Nephrol 2012;36:405-411. 